\title{
The role of phonology during visual word learning in adults: An integrative review
}

\author{
Gabriela Meade $^{1,2}$ (D) \\ Published online: 17 August 2019 \\ (C) The Psychonomic Society, Inc. 2020
}

\begin{abstract}
Throughout their lifetime, adults learn new words in their native lannguage, and potentially also in a second language. However, they do so with variable levels of success. In the auditory word learning literature, some of this variability has been attributed to phonological skills, including decoding and phonological short-term memory. Here I examine how the relationship between phonological skills and word learning applies to the visual modality. I define the availability of phonology in terms of (1) the extent to which it is biased by the learning environment, (2) the characteristics of the words to be learned, and (3) individual differences in phonological skills. Across these three areas of research, visual word learning improves when phonology is made more available to adult learners, suggesting that phonology can facilitate learning across modalities. However, the facilitation is largely specific to alphabetic languages, which have predictable sublexical correspondences between orthography and phonology. Therefore, I propose that phonology bootstraps visual word learning by providing a secondary code that constrains and refines developing orthographic representations.
\end{abstract}

Keywords Adult word learning $\cdot$ Orthographic processing $\cdot$ Phonological recoding $\cdot$ Lexical quality

Adults continually learn new words in their native language (L1), and possibly also in a second language (L2), making vocabulary one of the few aspects of language that continues to expand throughout the lifespan (e.g., Ramscar, Hendrix, Shaoul, Milin, \& Baayen, 2014; Verhaeghen, 2003). Establishing a rich vocabulary is a key prerequisite for success in areas as varied as reading comprehension, syntax development, and foreign language proficiency (e.g., Meschyan \& Hernandez, 2002; Ricketts, Nation, \& Bishop, 2007). Whereas learning new words comes easy to some, it is a challenge for others, and the factors that underlie this variability remain poorly understood. Building on the growing evidence that strong phonological abilities improve the acquisition of new auditory word forms (e.g., Atkins \& Baddeley, 1998; Baddeley, Gathercole, \& Papagno, 1998; Gupta, 2003; Kaushanskaya \& Yoo, 2011; Majerus, Poncelet, Elsen, \& Van Der Linden, 2006; Martin \& Ellis, 2012; O’Brien, Segalowitz,

Gabriela Meade

meade.gabriela@gmail.com

1 San Diego State University, San Diego, CA, USA

2 University of California, San Diego, La Jolla, CA, USA
Freed, \& Collentine, 2007), I address how phonology contributes to successful learning of visual word forms in adults. Phonology is highlighted both in models of learning to read in children (e.g., Ehri, 1992; Perfetti, 1992; Share, 1995) and in recognition of existing visual word forms in adults (e.g., Grainger \& Holcomb, 2009; Grainger \& Ziegler, 2011; Perry, Ziegler, \& Zorzi, 2007; Rastle \& Brysbaert, 2006). It would make sense then that phonology is also involved in orthographic word learning in adults. Preliminary support for this hypothesis comes from the studies reviewed here. Ultimately, identifying the role of phonology during visual word learning will improve our understanding of the mechanisms by which phonological skills bootstrap word learning, and will contribute to the development of successful remediation strategies for adults who have difficulty committing new words to their lexicon.

\section{Phonology constrains the orthographic code: A developmental perspective}

Phonology is assumed to play a major role in the acquisition of novel visual word forms as children learn to read. This is exemplified by Share's $(1995,2008)$ self-teaching hypothesis, 
which posits that successful phonological recoding enables children to identify unfamiliar words on their own as they read, and serves as the primary way in which they learn new visual word forms. Following Share (1995), I use the term phonological recoding to refer to the set of "processes by which speech-based information is derived from, or activated by, printed letter strings" (p. 152). In turn, successful phonological recoding enables children to acquire word-specific orthographic representations and to recognize orthographic regularities in the language. As orthographic knowledge progresses, the role of phonological recoding in word learning is hypothesized to diminish (e.g., Sprenger-Charolles, Siegel, Béchennec, \& Serniclaes, 2003). Few scholars have considered how phonology might continue to shape orthographic word learning into adulthood.

In examining the role that phonology plays during orthographic word learning, it is important to bear in mind that phonological recoding takes a different form in beginning readers than it does in adult readers who have extensive experience with the written word. Recoding orthography into phonology is explicit and effortful for beginning readers, whereas coactivation of phonology is more automatic during the processing of both known and unknown words in adults (e.g., Fariña, Duñabeitia, \& Carreiras, 2017; Grainger, Kiyonaga, \& Holcomb, 2006; Rastle \& Brysbaert, 2006). Beginning readers only possess a restricted set of grapheme-tophoneme correspondences (GPCs), but with time and reading experience, these correspondences become increasingly nuanced and context specific, at least in some models. For example, a beginning reader might first associate the grapheme oo with the sound $/ \mathrm{u} /$, and would therefore produce the vowels in the words spoon and look identically. An adult reader who has learned contextual (i.e., lexicalized) rules about the pronunciation of this vowel in English would differentiate the words and generalize these rules to the pseudowords bloon and blook (see, e.g., Treiman, Kessler, \& Bick, 2003). To develop context-specific GPCs, the experienced reader must be able to process more than one grapheme at a time. Ehri (1992) referred to this skill as the cipher, which she defined as the ability to establish connections in memory between entire sequences of letters and the corresponding phonemes (see also Grainger \& Ziegler, 2011). By adulthood, typical readers have mastered this skill and are able to use it to improve their learning of new visual words.

In the specific context of visual word learning, the purpose of phonological recoding also differs between children and adults. Beginning readers usually learn to recognize and spell common words that already exist in their spoken vocabulary (e.g., Ehri, 1992), whereas adults generally learn words that they do not know and are required to learn the visual and auditory forms simultaneously. This is true whether adults are learning advanced L1 vocabulary or words in a new language, with the added potential complication of unfamiliar graphemes and phonemes or different GPCs in the case of a new language. As a result, beginning readers typically phonologically recode visual words in order to match them with existing phonological lexical representations and extract meaning, but adults usually have no phonological lexical representations with which to match new words. All of these differences motivate the question of how recoding facilitates orthographic learning in adult readers.

As a starting point, I suggest that phonology might improve visual word learning in adults by constraining the orthographic code (see also Grainger, 2008; Perry et al., 2007). Grainger and Ziegler (2011) have proposed that visual words can be processed along two distinct routes. The coarse-grained route makes use of relative letter positions (i.e., open bigrams) and provides a fast track from orthography to semantics. Along the fine-grained route, letters and commonly occurring multiletter graphemes (e.g., th, ch, ing) are assigned specific positions and are phonologically recoded. Thus, recognition of visual words along the fine-grained route involves stronger coactivation of phonology at both the sublexical and lexical levels. The route that is used depends on many factors, including the amount and type of experience that the reader has had with each word. When first exposed to a word, adult learners likely rely on the fine-grained route and use sublexical GPCs to begin constructing a phonological representation. Following additional exposures, the learner acquires the ability to process the new word along the more efficient coarsegrained route. A similar dichotomy, though in the opposite direction, is reflected in the lexical quality hypothesis (Perfetti, 1992, 2007). In that framework, a high-quality representation is both precise and redundant. It is precise in that each letter is represented in its correct position, and redundant in that the same form information is represented orthographically and phonologically, reminiscent of the fine-grained route. The redundancy contributes to automatic recognition of known words in addition to bootstrapping identification of unknown words. Perfetti (1992) argued that beginning readers rely more on orthography than on phonology to recognize less familiar visual words that have lower-quality representations. This is because young readers lack contextsensitive GPCs that enable them to correctly sound out the word and match it with an existing phonological lexical representation. By adulthood, context-sensitive GPCs should be well established, leading to more accurate phonological codes for unfamiliar words, at least in the L1. As a result, phonological codes are arguably even more reliable learning cues for adults than for beginning readers.

Interestingly, both theories associate phonology with the processing of more precise orthographic representations. This makes it even more important to consider how phonology is involved in the tuning of new orthographic representations during learning. Perhaps the best illustration of this is to imagine writing a newly learned word; one might break the auditory 
word down into sequenced chunks (e.g., syllables, individual phonemes) and use that information to structure the spelling (i.e., to put each letter in the right position). Knowing what the word sounds like restricts the possible spellings. Phonology serves as an additional memory trace for the new word and, because of its special relationship with orthography, can be used to tune the orthographic representation. In short, my working hypothesis is that phonology biases the fine-grained orthographic route and facilitates the development of more precise orthographic representations for novel words in adults.

The remainder of this article puts this hypothesis to the test by reviewing how the availability of phonology affects the learning of visual word forms in adults. I define the availability of phonology in three ways: (1) the extent to which the learning environment encourages coactivation of phonology, (2) whether the characteristics of the novel words lend themselves to phonological recoding, and (3) individual differences in phonological skills among learners. Overall, converging evidence from these three areas of research indicates that enhancing the availability of phonology improves orthographic word learning, in part by facilitating the development of more precise orthographic representations.

\section{Directing attention toward phonology improves learning}

One approach to examining how phonological availability affects orthographic word learning is to compare learning outcomes in environments that bias the co-activation of phonology with those that do not (e.g., Chalmers \& Burt, 2008; Kaushanskaya \& Yoo, 2011; Sandak et al., 2004; Taylor, Plunkett, \& Nation, 2011). The predictions here are straightforward; assuming that phonology bootstraps orthographic word learning, emphasizing phonology should improve learning outcomes and lead to more precise (i.e., fine-grained) orthographic representations. Perhaps the most obvious way to examine this would be to explicitly provide the phonological codes for one set of words but not the other, and to test for differences in orthographic learning between the two sets. In one such study, Taylor et al. (2011) compared learning of an artificial orthography in a group that was preexposed to the lexical phonology for the new words versus a baseline group that received no preexposure. Unsurprisingly, participants who had been preexposed to the lexical phonology read the new words aloud more accurately the first time. However, preexposure to phonology did not affect reading accuracy by the end of training, nor did it improve performance on an oldnew decision task with orthographically similar distractors. The latter could indicate that lexical phonology did not improve learning of the orthographic form, but it could also be a ceiling effect. Chalmers and Burt (2008, Exp. 1) provided more convincing evidence for the relationship between phonology and orthographic learning. They compared learning of novel multisyllabic visual words presented with versus without the pronunciation. In an unexpected spelling recognition test after learning, participants were better at differentiating between the correct spelling of the new words (e.g., misvearance) and phonologically plausible alternatives (e.g., misveerence) if they had learned the words with pronunciation. Critically, phonology could not directly help participants in this task, because the two alternatives shared the same phonology. Thus, contrary to the previous study by Taylor et al. (2011), these results indicate that explicitly providing the phonological form of the new words improves the learning of the orthographic forms.

Changing the learning environment by instructing learners to focus on phonology also improves orthographic learning. For example, in a second experiment, Chalmers and Burt (2008) showed learners new words and their meanings (i.e., without phonology) and manipulated the extent to which phonology was biased by the learning task. In the orthographicencoding task, participants indicated whether there was one or more than one consonant cluster in the novel word. In the phonological-encoding task, participants indicated whether or not the target letter was in the stressed syllable. Spelling recognition accuracy was higher in the condition that biased activation of phonology than in the condition that only biased orthography. Accuracy in a cued-recall task in which participants had to the spell the novel words themselves was also higher following the phonological learning task. Along similar lines, Sandak et al. (2004) found that biasing learners' attention toward phonology, by asking them to do a rhyme judgment, led to faster naming times (but similar accuracy) relative to an orthographic baseline in which they made judgments about the consonant-vowel structure of the words. Together, these studies demonstrate that phonological task instructions help refine orthographic representations and help establish efficient connections between those new representations and the corresponding phonology.

Conversely, visual word learning is negatively impacted by making phonology less available through articulatory suppression (e.g., Papagno, Valentine, \& Baddeley, 1991; see Share, 1999, for similar evidence with children learners). Papagno and colleagues investigated the acquisition of L2 Russian words (that were pronounceable following transliteration into the Roman alphabet) paired with their L1 Italian translations. The authors found higher backward translation $(\mathrm{L} 2 \rightarrow \mathrm{L} 1)$ accuracy for Russian words learned during finger tapping than for those learned while the participant repeated the same nonsense syllable (i.e., articulatory suppression). There was no such interaction for paired-associate learning with familiar L1 words. The researchers interpreted this pattern to suggest that articulatory suppression disrupts learning 
by interfering with phonological recoding of the unfamiliar Russian words. This finding is important because it suggests that these learners were using phonological recoding under normal circumstances (i.e., even when it was not explicitly motivated by the learning environment).

One prominent exception to the pattern of improved word learning with explicit phonology is languages with nonalphabetic orthographies. Languages with alphabetic orthographies (e.g., English and Korean) have a systematic correspondence between graphemes and phonemes, whereas languages with nonalphabetic orthographies (e.g., Chinese) do not have the same reliable sublexical structure. In the case of Chinese, directing attention toward phonology has been shown to benefit the learning of phonological form, but not the learning of orthographic form (e.g., Cao et al., 2017; Guan, Liu, Chan, Ye, \& Perfetti, 2011; Guan, Perfetti, \& Meng, 2015; Lagarrigue et al., 2017). For example, Lagarrigue and colleagues recently reported a study in which native French speakers who were enrolled in a basic Chinese university course learned a small set of Chinese characters in the laboratory. For half of the characters, the learners pronounced the pinyin (i.e., phonology), and for the other half of the characters, they reproduced the orthographic form of the character. There were no differences between the two sets of characters in backward translation accuracy during or after learning. In a similar study, Yum (2013) compared the learning of Chinese characters with versus without phonology in native English speakers who had had no formal exposure to Chinese. Especially early during learning, the participants in the visual-only group outperformed learners in the visual/ auditory group in backward translation and translation recognition tasks. The increased performance in the group who only saw the visual forms might have been due to their ability to dedicate more attentional resources to learning the complex Chinese characters, rather than dividing attention between learning both the complex characters and their pronunciations. Together, these results suggest that phonology has less of an influence on the learning of complex nonalphabetic orthographies such as Chinese, and might even be counterproductive.

\section{Words with predictable phonological codes are learned better}

The availability of phonology can also be manipulated by changing the characteristics of the novel words. In the studies reviewed in this section, all of the words were taught in the same learning environment, and the critical manipulation was how well the phonological codes of the novel words aligned with the learners' expectations or existing knowledge (e.g., Bartolotti \& Marian, 2017, 2019; Brusnighan, Morris, Folk, \& Lowell, 2014; Burt \& Blackwell, 2008; Burt \& Butterworth, 1996; Hamada \& Koda, 2008; Howland \&
Liederman, 2013; McKague, Davis, Pratt, \& Johnston, 2008; McKay, Davis, Savage, \& Castles, 2008; Taylor et al., 2011). Orthographic learning should improve when the learners' knowledge coincides with the sublexical mappings between orthography and phonology in the novel words. Indeed, when Burt and Butterworth compared learning of words with high (e.g., diskangle), medium (e.g., dispeign), and low (e.g., dysthoegm) pronounceability, they found that accuracy on orthographic recognition and recall tasks increased as a function of pronounceability. Presumably, phonological codes were more readily available for highly pronounceable words, and this additional information could be used to strengthen and tune the orthographic representations. However, the effect could also be due to other differences between the conditions, most notably orthographic regularity (i.e., independent of phonology. Following a similar approach, Bartolotti and Marian (2017)) taught participants pseudowords with a range of "wordlikeness," which they defined in terms of orthographic and phonological neighborhood density and position-specific segment frequencies in L1 English. Participants were tested in a recognition task, in which they saw a picture and picked the correct novel word name from among four possibilities, and in a written production task, in which they saw a picture and typed the name. In both tasks, accuracy was higher and responses were faster for novel words that were wordlike than for those that were not (see also Meade, Midgley, Dijkstra, \& Holcomb, 2018). However, the effects of orthographic and phonological wordlikeness were confounded. When the authors analyzed only a subset of the words that were carefully controlled for phonological wordlikeness, but that still differed in orthographic wordlikeness, the benefit for wordlike items persisted in the production task, but disappeared in the recognition task. Thus, both orthographic and phonological regularities appeared to improve learning outcomes in that study, but to different degrees as a function of task. Further dissociating orthographic and phonological regularities is a critical challenge for future research aiming to pinpoint the role of phonology in orthographic word learning.

A related set of studies has demonstrated that words with consistent sublexical mappings between orthographic and phonological codes are learned better than words with inconsistent mappings (e.g., Burt \& Blackwell, 2008; Hamada \& Koda, 2008; McKague et al., 2008; McKay et al., 2008; Taylor et al., 2011). This comparison addresses the confound between orthography and phonology, because the orthographic forms can be stable but assigned different pronunciations. For example, McKay and colleagues taught participants pseudowords with letter sequences that have consistent pronunciations based on L1 English GPCs (e.g., -ean is always pronounced as /i:n/). They manipulated feedforward (orthography $\rightarrow$ phonology) consistency by maintaining this pronunciation for pseudowords in the consistent condition (e.g., trean 
was pronounced as /tii:n/), and changing it for pseudowords in the inconsistent condition (e.g., trean was pronounced as /tı\&n/). In other L1 English contexts, the correspondences between the letters and the inconsistent sounds were possible (e.g., ea can be pronounced as $/ \varepsilon /$, as in the word dead), but they violated expectations in that particular context. Participants named the consistent words more quickly and accurately than the inconsistent words. The errors that learners made on inconsistent trials often involved overregularization of English GPCs (e.g., pronouncing drean as /dri:n/), strengthening the argument that they were activating phonological codes based on their English knowledge in order to learn the orthographic words. In the inconsistent condition, the Englishderived phonology conflicted with the phonology that participants needed to learn, and so hindered learning. Taylor et al. (2011) extended these findings in a study with an artificial orthography and a consistency manipulation within the L2 (rather than by relying on L1 GPCs). During learning, participants saw novel words in an unfamiliar orthography, heard their pronunciation, and repeated the word aloud. Consistent characters corresponded to only one sound. Inconsistent characters were mapped to one of two vowel sounds, depending on the environment in which they occurred. Learners produced the words with consistent vowels more accurately than those with inconsistent vowels. After learning, they named novel words in the same orthography, and did so with higher accuracy for the words that contained consistent vowel characters. Interestingly, in both these studies the inconsistent words benefited more than the consistent words from additional learning supports (i.e., more frequent exposures, the addition of semantics), suggesting that other types of information can repair learning when phonology is less reliable or less available. Note, however, that the naming tasks that were used are not a direct measure of the precision of the orthographic representation and could be reflecting differences in the strength of the connections from orthography to phonology.

Defining consistency in the feedback (phonology $\rightarrow$ orthography) direction, there are some studies with spelling tasks that have shown that consistency between the codes improves the precision of orthographic representations specifically (e.g., Burt \& Blackwell, 2008; McKague et al., 2008). In the study reported by Burt and Blackwell, the learning phase consisted of pronouncing novel pseudowords presented on the screen and reading their definitions. Pronouncing the words was straightforward, because each word was consistent in the feedforward (orthography $\rightarrow$ phonology) direction and had only one plausible pronunciation based on English GPCs (e.g., groal and mish have consistent pronunciations among native English speakers). After learning, participants were slower and less accurate to spell the feedback-inconsistent words (e.g., groal could also be spelled as grole) than the feedback-consistent words (e.g., there are no alternate spellings for the pseudoword mish). Participants who were skilled spellers in English were especially likely to make phonologically plausible mistakes (e.g., to spell grole instead of groal). In other words, learners appeared to be phonologically recoding the novel words and then using this phonological code to generate the orthographic representation during the spelling task. For feedback-consistent words, this was a foolproof strategy and led to high accuracy. For feedback-inconsistent words, the phonological representation corresponded to multiple possible spellings, and the learner had to rely on orthographic memory traces to remember which of them was correct. Taken together, the finding that ambiguous sublexical mappings between orthography and phonology disrupt learning suggests that phonology is involved in the tuning of new orthographic representations. Although these studies largely focused on wordlikeness or inconsistency in the learner's L1, knowledge about these patterns in the L2 also affects learning once a minimal level of L2 proficiency is achieved (e.g., Hamada \& Koda, 2008; Treutlein, Schöler, \& Landerl, 2017).

Beyond sublexical mappings, the familiarity of phonological representations at the lexical level also influences orthographic learning. Brusnighan et al. (2014) investigated how adults learn novel pseudohomophonic (e.g., skwosh has the same pronunciation as squash, but was defined as a type of musical instrument) and non-pseudohomophonic words embedded in L1 sentences. This is another approach to avoiding the confound between phonological and orthographic regularities, since all of the novel words were orthographically legal and the two conditions were balanced for orthographic regularity. By isolating lexical phonology in this way, they found more regressions from the first looks at the target to the preceding context for novel pseudohomophonic words than for non-pseudohomophonic words. The authors argued that learners were automatically co-activating phonology and had difficulty associating a known phonological lexical form with a new orthography and meaning. In a second experiment with a similar design, the authors found that participants learned the meanings of the two types of words equally well, but spelling accuracy was higher for the pseudohomophonic words than for the non-pseudohomophonic words. The familiarity of the pseudohomophones following phonological recoding may have helped improve acquisition of the form of the orthographic word. An alternative explanation would be that learners were explicitly comparing the orthography of the pseudohomophone (e.g., skwosh) and its base word (e.g., squash) during learning, and that this effortful analysis led to better (i.e., more precise) learning of the orthographic form. In sum, studies that have modulated the availability of phonology by manipulating word-level characteristics are largely consistent with the hypothesis that orthographic representations are more reliable for words that align with the learners' knowledge about sublexical and lexical phonology. 


\section{Individuals with better phonological skills are better orthographic learners}

The degree to which individual learners are able to utilize these constraining phonological codes or to inhibit the conflicting ones varies considerably. The third and final way in which I define phonological availability is in terms of individual differences in phonological skills. Here the reasoning goes that if phonology tunes orthographic representations during learning, then individuals who have strong phonological skills should acquire more precise visual word form representations. Indeed, there is evidence to suggest that phonological memory and decoding abilities correlate with orthographic word learning and yield larger vocabularies in adults (e.g., Bartolotti \& Marian, 2017; Brennan \& Booth, 2015; Chalmers \& Burt, 2008; Howland \& Liederman, 2013; Ocal \& Ehri, 2017; Service \& Kohonen, 1995; cf. Weekes, 2018). As described above, participants in the learning study reported by Bartolotti and Marian (2017) saw pictures and had to type the pseudowords with which they had been associated over five learning blocks within the same session. Accuracy on the typing task with novel pseudowords improved faster for participants with larger phonological memory capacity, as measured by the digit span and nonword repetition subtests of the Comprehensive Test of Phonological Processing (Wagner, Torgesen, \& Rashotte, 1999). Together with other studies in which relationships between phonological skill and performance in spelling production tasks have been reported (e.g., Chalmers \& Burt, 2008), these results demonstrate that phonology improves the tuning of orthographic representations. The directionality of this relationship is difficult to pinpoint. However, some preliminary evidence of causality comes from the finding that L1 phonological abilities in early childhood correlate with later L2 learning success (e.g., Sparks, Patton, Ganschow, Humbach, \& Javorsky, 2006).

A similar relationship has been established for visual word learning in the L2, which is influenced by phonological skills in both the L1 and the L2 (Cao et al., 2017; Hamada \& Koda, 2008; Meschyan \& Hernandez, 2002; Sparks et al., 1997; Sparks et al., 2006; Weekes, 2018). For example, Meschyan and Hernandez found that L1 decoding ability predicted L2 vocabulary size and L2 competency in a group of classroom English-Spanish learners (see also Hummel \& French, 2016). However, statistical models suggested that this relationship was mediated by L2 decoding ability: Strong L1 decoding scores led to strong L2 decoding scores, which in turn improved L2 learning outcomes. Interestingly, decoding skills only transfer across languages in this way if both languages are alphabetic. Learners who have a nonalphabetic L1 have less experience decoding, which alters the transfer of these skills across languages (e.g., Hamada \& Koda, 2008; Mori, 1998; Wang, Koda, \& Perfetti, 2003). For example, Hamada and Koda (2008) found that the correlations between L2 phonological skills and the spelling of newly learned L2 words were weaker for Chinese-English learners than for Korean-English learners, where the latter group had extensive experience decoding in their alphabetic L1. In addition, if the target L2 is not alphabetic, phonological skills no longer contribute to visual word learning. Cao et al. (2017) found that phonological awareness in L1 English correlated positively with the ability to produce the meaning and pronunciation of Spanish words, but not of Chinese characters, within the same group of learners. Thus, phonological skills appear to affect the learning of visual word forms in the L1 and the L2, but only when the relationship between orthography and phonology is predictable, as in alphabetic languages.

These correlations within the population of typical readers extend to adults with dyslexia, who are at one extreme of the spectrum of phonological abilities. The predominant form of dyslexia is characterized by phonological deficits that persist into adulthood (e.g., Snowling, Nation, Moxham, Gallagher, $\&$ Frith, 1997). These deficits can lead to problems associating orthography and phonology (e.g., Blau, van Atteveldt, Ekkebus, Goebel, \& Blomert, 2009; Pitchford, Ledgeway, \& Masterson, 2009). Thus, adults with a history of dyslexia may show weaker co-activation of phonology during visual word learning, or may be less able to capitalize on phonology to tune orthographic representations. Very few studies have investigated orthographic word learning in this population, and the different aims and experimental designs of the studies make it difficult to draw strong conclusions. However, the available evidence indicates that adults with dyslexia may face difficulties learning new visual word forms, perhaps because they rely on an inefficient incremental phonological-recoding approach for longer than typical adult readers (e.g., Di Betta \& Romani, 2006; Howland \& Liederman, 2013; Kwok \& Ellis, 2014; Samara \& Caravolas, 2017). This conclusion strengthens the overarching argument that individual differences in phonological abilities affect orthographic learning.

\section{Conclusions and future directions}

Overall, the studies reviewed here are consistent with the hypothesis that phonology bootstraps orthographic learning. Increasing the availability of phonology - defined in terms of learning environment, word characteristics, and individual differences - improves orthographic word learning, at least in alphabetic languages. Contrariwise, making phonology less available (e.g., with articulatory suppression or unpredictable/unexpected pronunciations) has a negative impact on learning. The latter finding is critical for establishing that learners engage phonological recoding on their own and that the experimental manipulations described here only serve to facilitate or hinder that process. 
Is phonology special? One might expect that orthographic learning would improve whenever additional information is made available. Indeed, providing a meaning for the new word or biasing semantics has also been shown to improve word learning (e.g., Angwin, Phua, \& Copland, 2014; Barcroft \& Sunderman, 2008), although not more than phonology (e.g., Taylor, Davis, \& Rastle, 2017). That said, if the effect were more general and only due to including additional information, then biasing phonology should improve visual word learning across all languages and conditions. Instead, the specificity of the relationship to alphabetic orthographies indicates that the advantage afforded by phonology goes beyond an additional memory trace for the word; as hypothesized, the sublexical relationship between the two codes is critical.

Identifying the exact mechanism by which phonology improves orthographic learning remains difficult. Part of the challenge is that so few of the studies reviewed here included a measure of the precision of the orthographic representation itself as it was being accessed. Although there is some evidence to suggest that spelling measures yield information about the precision of lexical representations and the patterns of lexical processing for known words (e.g., Andrews \& Hersch, 2010; Andrews \& Lo, 2012; Meade, Grainger, Midgley, Emmorey, \& Holcomb, 2018), research in this area would benefit from the development of methods that offer more nuanced measures of orthographic precision. These measures would need to be employed at discrete time points during learning in order to track changes in the precision of orthographic representations. Capturing this trajectory of individual representations over the course of learning is of fundamental theoretical importance.

Another avenue of research to pursue is the study of orthographic precision and orthographic learning in readers of alphabetic languages who are not experts in phonology. Adults who have dyslexia or are profoundly deaf still typically have a functional orthographic lexicon, despite having restricted access to phonology. Either the phonological skills that they do have are sufficient (see, e.g., Hanson \& McGarr, 1989, and MacSweeney, Goswami, \& Neville, 2013, for evidence that deaf readers have some level of explicit phonological knowledge) or they use compensatory strategies to develop precise orthographic representations. The limited research on adult readers with dyslexia that I have touched upon here suggests that they are using sublexical codes, but ineffectively (e.g., Di Betta \& Romani, 2006; Howland \& Liederman, 2013; Kwok \& Ellis, 2014; Samara \& Caravolas, 2017). To my knowledge, there has been no study of visual word learning in deaf adults, but recent evidence suggests that they are able to achieve levels of orthographic precision similar to those of their hearing counterparts for known words (see, e.g., Fariña et al., 2017). Adapting some of the manipulations described here for adult readers who have limited access to phonology would allow insight into the level of phonology that is necessary for developing precise orthographic representations and into the strategies that might be useful for improving orthographic precision when phonology is suboptimal or insufficient.

Coupled with this issue of poor phonological skills is the question of how well explicit phonological training improves orthographic word learning, or whether it improves learning at all (see, e.g., de Jong, Seveke, \& van Veen, 2000, and Torgesen, Morgan, \& Davis, 1992, who addressed similar questions in young children). If phonological skills underlie successful orthographic word learning, then strengthening phonological skills should transfer to improvements in orthographic learning. Establishing causality in this way would strengthen the relationship between the two skills and make this line of research more informative for classroom teachers. Overall, the literature reviewed here establishes an empirical foundation for the hypothesis that phonology bootstraps orthographic word learning in adults, but many questions remain as to the exact role that phonology plays and how specific or generalizable the benefits are.

Acknowledgments This material was supported by National Science Foundation Grant No. BCS-1823955 and Graduate Research Fellowship No. 2016196208 and by a Women in Cognitive Science Travel Award to Initiate International Research Collaborations. I thank Phil Holcomb, Jonathan Grainger, and Mathieu Declerck for insightful discussions and debates on these topics, and the members of my dissertation committee for comments on a previous version of the review.

\section{References}

Andrews, S., \& Hersch, J. (2010). Lexical precision in skilled readers: Individual differences in masked neighbor priming. Journal of Experimental Psychology, 139, 299-318. https://doi.org/10.1037/ a0018366

Andrews, S., \& Lo, S. (2012). Not all skilled readers have cracked the code: Individual differences in masked form priming. Journal of Experimental Psychology: Learning, Memory, and Cognition, 38, 152-163. https://doi.org/10.1037/a0024953

Angwin, A. J., Phua, B., \& Copland, D. A. (2014). Using semantics to enhance new word learning: An ERP investigation. Neuropsychologia, 59, 169-178. https://doi.org/10.1016/j. neuropsychologia.2014.05.002

Atkins, P. W. B., \& Baddeley, A. D. (1998). Working memory and distributed vocabulary learning. Applied Psycholinguistics, 19, 537552. https://doi.org/10.1017/S0142716400010353

Baddeley, A. D., Gathercole, S. E., \& Papagno, C. (1998). The phonological loop as a language learning device. Psychological Review, 105, 158-173. https://doi.org/10.1037/0033-295X.105.1.158

Barcroft, J., \& Sunderman, G. (2008). Learning new words for objects and nonobjects: Theoretical and methodological implications. Mental Lexicon, 3, 325-348. https://doi.org/10.1075/ml.3.3.05bar

Bartolotti, J., \& Marian, V. (2017). Orthographic knowledge and lexical form influence vocabulary learning. Applied Psycholinguistics, 38, 427-456. https://doi.org/10.1017/S0142716416000242

Bartolotti, J., \& Marian, V. (2019). Learning and processing of orthography-to-phonology mappings in a third language. International Journal of Multilingualism. https://doi.org/10.1080/ 14790718.2017.1423073

Blau, V., van Atteveldt, N., Ekkebus, M., Goebel, R., \& Blomert, L. (2009). Reduced neural integration for letters and speech sounds 
links phonological and reading deficits in adult dyslexia. Current Biology, 19, 503-508. https://doi.org/10.1016/j.cub.2009.01.065

Brennan, C., \& Booth, J. R. (2015). Large grain instruction and phonological awareness skill influence rime sensitivity, processing speed, and early decoding skill in adult L2 learners. Reading and Writing, 28, 917-938. https://doi.org/10.1007/s11145-015-9555-2

Brusnighan, S. M., Morris, R. K., Folk, J. R., \& Lowell, R. (2014). The role of phonology in incidental vocabulary acquisition during silent reading. Journal of Cognitive Psychology, 26, 871-892. https://doi. org/10.1080/20445911.2014.965713

Burt, J. S., \& Blackwell, P. (2008). Sound-spelling consistency in adult' orthographic learning. Journal of Research in Reading, 31, 77-96. https://doi.org/10.1111/j.1467-9817.2007.00362.x

Burt, J. S., \& Butterworth, P. (1996). Spelling in adults: Orthographic transparency, learning new letter strings and reading accuracy. European Journal of Cognitive Psychology, 8, 3-43. https://doi. org/10.1080/095414496383194

Cao, F., Sussman, B. L., Rios, V., Yan, X., Wang, Z., Spray, G. J., \& Mack, R. M. (2017). Different mechanisms in learning different second languages: Evidence from English speakers learning Chinese and Spanish. NeuroImage, 148, 284-295. https://doi.org/ 10.1016/j.neuroimage.2017.01.042

Chalmers, K. A., \& Burt, J. S. (2008). Phonological and semantic information in adults' orthographic learning. Acta Psychologica, 128, 162-175. https://doi.org/10.1016/j.actpsy.2007.12.003

Coltheart, M., Rastle, K., Perry, C., Langdon, R., \& Ziegler, J. (2001). DRC: A dual route cascaded model of visual word recognition and reading aloud. Psychological Review, 108, 204-256. https://doi.org/ 10.1037/0033-295X.108.1.204

de Jong, P. F., Seveke, M.-J., \& van Veen, M. (2000). Phonological sensitivity and the acquisition of new words in children. Journal of Experimental Child Psychology, 76, 275-301. https://doi.org/10. 1006/jecp.1999.2549

Di Betta, A. M., \& Romani, C. (2006). Lexical learning with dysgraphia in a group of adults with developmental dyslexia. Cognitive Neuropsychology, 23, 376-400. https://doi.org/10.1080/ 02643290442000545

Ehri, L. C. (1992). Reconceptualizing the development of sight word reading and its relationship to recoding. In P. B. Gough, L. C. Ehri, \& R. Treiman (Eds.), Reading acquisition (pp. 107-143). London, UK: Taylor \& Francis.

Fariña, N., Duñabeitia, J. A., \& Carreiras, M. (2017). Phonological and orthographic coding in deaf skilled readers. Cognition, 168, 27-33. https://doi.org/10.1016/j.cognition.2017.06.015

Grainger, J. (2008). Cracking the orthographic code: An introduction. Language and Cognitive Processes, 23, 1-35. https://doi.org/10. 1080/01690960701578013

Grainger, J., \& Holcomb, P. J. (2009). Watching the word go by: On the time-course of component processes in visual word recognition. Language and Linguistics Compass, 3, 128-156. https://doi.org/ 10.1111/j.1749-818X.2008.00121.x

Grainger, J., Kiyonaga, K., \& Holcomb, P. J. (2006). The time course of orthographic and phonological code activation. Psychological Science, 17, 1021-1026. https://doi.org/10.1111/j.1467-9280.2006. 01821.x

Grainger, J., \& Ziegler, J. (2011). A dual-route approach to orthographic processing. Frontiers in Psychology, 2, 54:1-13. https://doi.org/10. 3389/fpsyg.2011.00054

Guan, C. Q., Liu, Y., Chan, D. H. L., Ye, F., \& Perfetti, C. A. (2011). Writing strengthens orthography and alphabetic-coding strengthens phonology in learning to read Chinese. Journal of Educational Psychology, 103, 509-522. https://doi.org/10.1037/a0023730

Guan, C. Q., Perfetti, C. A., \& Meng, W. (2015). Writing quality predicts Chinese learning. Reading and Writing, 28, 763-795. https://doi. org/10.1007/s11145-015-9549-0
Gupta, P. (2003). Examining the relationship between word learning, nonword repetition, and immediate serial recall in adults. Quarterly Journal of Experimental Psychology, 56, 1213-1236. https://doi.org/10.1080/02724980343000071

Hamada, M., \& Koda, K. (2008). Influence of first language orthographic experience on second language decoding and word learning. Language Learning, 58, 1-31. https://doi.org/10.1111/j.14679922.2007.00433.x

Hanson, V. L., \& McGarr, N. S. (1989). Rhyme generation by deaf adults. Journal of Speech, Language, and Hearing Research, 32, 2-11.

Howland, K. A., \& Liederman, J. (2013). Beyond decoding: Adults with dyslexia have trouble forming unified lexical representations across pseudoword learning episodes. Journal of Speech, Language, and Hearing Research, 56, 1009-1022. https://doi.org/10.1044/10924388(2012/11-0252)

Hummel, K. M., \& French, L. M. (2016). Phonological memory and aptitude components: Contributions to second language proficiency. Learning and Individual Differences, 51, 249-255. https://doi.org/ 10.1016/j.lindif.2016.08.016

Kaushanskaya, M., \& Yoo, J. (2011). Rehearsal effects in adult word learning. Language and Cognitive Processes, 26, 121-148. https:// doi.org/10.1080/01690965.2010.486579

Kwok, R. K. W., \& Ellis, A. W. (2014). Visual word learning in adults with dyslexia. Frontiers in Human Neuroscience, 8, 264:1-12. https://doi.org/10.3389/fnhum.2014.00264

Lagarrigue, A., Longcamp, M., Anton, J.-L., Nazarian, B., Prévot, L., Velay, J.-L., . . Frenck-Mestre, C. (2017). Activation of writingspecific brain regions when reading Chinese as a second language: Effects of training modality and transfer to novel characters. Neuropsychologia, 97, 83-97. https://doi.org/10.1016/j. neuropsychologia.2017.01.026

MacSweeney, M., Goswami, U., \& Neville, H. J. (2013). The neurobiology of rhyme judgment by deaf and hearing adults: An ERP study. Journal of Cognitive Neuroscience, 25, 1037-1048. https://doi.org/ 10.1162/jocn_a_00373

Majerus, S., Poncelet, M., Elsen, B., \& Van Der Linden, M. (2006) Exploring the relationship between new word learning and shortterm memory for serial order recall, item recall, and item recognition. European Journal of Cognitive Psychology, 18, 848-873. https://doi.org/10.1080/09541440500446476

Martin, K. I., \& Ellis, N. C. (2012). The roles of phonological short-term memory and working memory in L2 grammar and vocabulary learning. Studies in Second Language Acquisition, 34, 379-413. https:// doi.org/10.1017/S0272263112000125

McKague, M., Davis, C., Pratt, C., \& Johnston, M. B. (2008). The role of feedback from phonology to orthography in orthographic learning: An extension of item-based accounts. Journal of Research in Reading, 31, 55-76. https://doi.org/10.1111/j.1467-9817.2007. 00361.x

McKay, A., Davis, C., Savage, G., \& Castles, A. (2008). Semantic involvement in reading aloud: Evidence from a nonword training study. Journal of Experimental Psychology: Learning, Memory, and Cognition, 34, 1495-1517. https://doi.org/10.1037/a0013357

Meade, G., Grainger, J., Midgley, K. J., Emmorey, K., \& Holcomb, P. J. (2018). From sublexical facilitation to lexical competition: ERP effects of masked neighbor priming. Brain Research, 1685, 29-41. https://doi.org/10.1016/j.brainres.2018.01.029

Meade, G., Midgley, K. J., Dijkstra, T., \& Holcomb, P. J. (2018). Crosslanguage neighborhood effects in learners indicative of an integrated lexicon. Journal of Cognitive Neuroscience, 30, 70-85. https://doi. org/10.1162/jocn_a_01184

Meade, G., Grainger, J., Midgley, K. J., Holcomb, P. J., \& Emmorey, K. (2019). ERP effects of masked orthographic neighbor priming in deaf readers. Language, Cognition and Neuroscience, 34(8), 1016-1026. https://doi.org/10.1080/23273798.2019.1614201 
Meschyan, G., \& Hernandez, A. E. (2002). Age of acquisition and word frequency: Determinants of object-naming speed and accuracy. Memory \& Cognition, 30, 262-269. https://doi.org/10.3758/ BF03195287

Mori, Y. (1998). Effects of first language and phonological accessibility on Kanji recognition. Modern Language Journal, 82, 69-82. https:// doi.org/10.1111/j.1540-4781.1998.tb02595.x

O’Brien, I., Segalowitz, N. S., Freed, B. F., \& Collentine, J. (2007). Phonological memory predicts second language oral fluency gains in adults. Studies in Second Language Acquisition, 29, 557-581. https://doi.org/10.1017/S027226310707043X

Ocal, T., \& Ehri, L. C. (2017). Spelling ability in college students predicted by decoding, print exposure, and vocabulary. Journal of College Reading and Learning, 47, 58-74. https://doi.org/10.1080/ 10790195.2016.1219242

Papagno, C., Valentine, T., \& Baddeley, A. D. (1991). Phonological short-term memory and foreign-language vocabulary learning. Journal of Memory and Language, 30, 331-347. https://doi.org/ 10.1016/0749-596X(91)90040-Q

Perfetti, C. A. (1992). The representation problem in reading acquisition. In P. B. Gough, L. C. Ehri, \& R. Treiman (Eds.), Reading acquisition (pp. 145-174). Hillsdale, NJ: Erlbaum.

Perfetti, C. A. (2007). Reading ability: Lexical quality to comprehension. Scientific Studies of Reading, 11, 357-383. https://doi.org/10.1080/ 10888430701530730

Perry, C., Ziegler, J., \& Zorzi, M. (2007). Nested incremental modeling in the development of computational theories: The CDP+ model of reading aloud. Psychological Review, 114, 273-315. https://doi. org/10.1037/0033-295X.114.2.273

Pitchford, N., Ledgeway, T., \& Masterson, J. (2009). Reduced orthographic learning in dyslexic adult readers: Evidence from patterns of letter search. Quarterly Journal of Experimental Psychology, 62, 99-113. https://doi.org/10.1080/17470210701823023

Ramscar, M., Hendrix, P., Shaoul, C., Milin, P., \& Baayen, H. (2014). The myth of cognitive decline: Non-linear dynamics of lifelong learning. Topics in Cognitive Science, 6, 5-42. https://doi.org/10.1111/tops. 12078

Rastle, K., \& Brysbaert, M. (2006). Masked phonological priming effects in English: Are they real? Do they matter? Cognitive Psychology, $53,97-145$.

Ricketts, J., Nation, K., \& Bishop, D. V. M. (2007). Vocabulary is important for some, but not all reading skills. Scientific Studies of Reading, 11, 235-257. https://doi.org/10.1080/10888430701344306

Samara, A., \& Caravolas, M. (2017). Artificial grammar learning in dyslexic and non-dyslexic adults: Implications for orthographic learning. Scientific Studies of Reading, 21, 76-97. https://doi.org/10. 1080/10888438.2016.1262865

Sandak, R., Mencl, W. E., Frost, S. J., Rueckl, J. G., Katz, L., Moore, D. L., . . Pugh, K. R. (2004). The neurobiology of adaptive learning in reading: A contrast of different training conditions. Cognitive, Affective, \& Behavioral Neuroscience, 4, 67-88. https://doi.org/10. 3758/CABN.4.1.67

Service, E., \& Kohonen, V. (1995). Is the relation between phonological memory and form learning accounted for by vocabulary acquisition? Applied Psycholinguistics, 16, 155-172. https://doi.org/10.1017/ S0142716400007062

Share, D. L. (1995). Phonological recoding and self teaching: Sine qua non of reading acquisition. Cognition, 55, 151-218. https://doi.org/ 10.1016/0010-0277(94)00645-2

Share, D. L. (1999). Phonological recoding and orthographic learning: A direct test of the self-teachinng hypothesis. Journal of Experimental Child Psychology, 72, 95-129. https://doi.org/10.1006/jecp.1998. 2481
Share, D. L. (2008). Orthographic learning, phonological recoding, and self-teaching. Advances in Child Development and Behavior, 36, 31-82. https://doi.org/10.1016/S0065-2407(08)00002-5

Snowling, M. J., Nation, K., Moxham, P., Gallagher, A., \& Frith, U. (1997). Phonological processing skills of dyslexia students in higher education: A preliminary report. Journal of Research in Reading, 20, 31-41. https://doi.org/10.1111/1467-9817.00018

Sparks, R. L., Ganschow, L., Patton, J., Artzer, M., Siebenhar, D., \& Plageman, M. (1997). Prediction of foreign language proficiency. Journal of Educational Psychology, 89, 549-561. https://doi.org/10. 1037/0022-0663.89.3.549

Sparks, R. L., Patton, J., Ganschow, L., Humbach, N., \& Javorsky, J. (2006). Native language predictors of foreign language proficiency and foreign language aptitude. Annals of Dyslexia, 56, 129-160. https://doi.org/10.1007/s11881-006-0006-2

Sprenger-Charolles, L., Siegel, L. S., Béchennec, D., \& Serniclaes, W. (2003). Development of phonological and orthographic processing in reading aloud, in silent reading, and in spelling: A four-year longitudinal study. Journal of Experimental Child Psychology, 84, 194-217. https://doi.org/10.1016/S0022-0965(03)00024-9

Taylor, J. S. H., Davis, M. H., \& Rastle, K. (2017). Comparing and validating methods of reading instruction using behavioural and neural findings in an artificial orthography. Journal of Experimental Psychology: General, 146, 826-858. https://doi.org/ $10.1037 / x g e 0000301$

Taylor, J. S. H., Plunkett, K., \& Nation, K. (2011). The influence of consistency, frequency, and semantics on learning to read: An artificial orthography paradigm. Journal of Experimental Psychology: Learning, Memory, and Cognition, 37, 60-76. https://doi.org/10. 1037/a0020126

Torgesen, J. K., Morgan, S. T., \& Davis, C. (1992). Effects of two types of phonological awareness training on word learning in kindergarten children. Journal of Educational Psychology, 84, 364-370. https:// doi.org/10.1037/0022-0663.84.3.364

Treiman, R., Kessler, B., \& Bick, S. (2003). Influence of consonantal context on the pronunciation of vowels: A comparison of human readers and computational models. Cognition, 88, 49-78. https:// doi.org/10.1016/S0010-0277(03)00003-9

Treutlein, A., Schöler, H., \& Landerl, K. (2017). Recoding strategies of German learners of English as a foreign language. Reading and Writing, 30, 1215-1230. https://doi.org/10.1007/s11145-016-97198

Verhaeghen, P. (2003). Aging and vocabulary score: A meta-analysis. Psychology and Aging, 18, 332-339. https://doi.org/10.1037/08827974.18.2.332

Wagner, R. K., Torgesen, J. K., \& Rashotte, C. A. (1999). Comprehensive test of phonological processing (CTOPP). Austin, TX: PRO-ED.

Wang, M., Koda, K., \& Perfetti, C. A. (2003). Alphabetic and nonalphabetic L1 effects in English word identification: A comparison of Korean and Chinese English L2 learners. Cognition, 87, 129149. https://doi.org/10.1016/s0010-0277(02)00232-9

Weekes, B. S. (2018). Learning written word vocabulary in a second language: Theoretical and practical implications. Bilingualism: Language and Cognition, 21, 585-597. https://doi.org/10.1017/ S1366728917000141

Yum, Y. N. (2013). An ERP study on adult second language word learning (Unpublished doctoral dissertation). Tufts University, Medford, MA.

Publisher's note Springer Nature remains neutral with regard to jurisdictional claims in published maps and institutional affiliations. 